\title{
Analisis Perbandingan DTM (Digital Terrain Model) dari LiDAR (Light Detection and Ranging) dan Foto Udara dalam Pembuatan Kontur Peta Rupa Bumi Indonesia
}

\author{
Novita Duantari dan Agung Budi Cahyono \\ Departemen Teknik Geomatika, Fakultas Teknik Sipil dan PerencanaanInstitut Teknologi Sepuluh \\ Nopember (ITS) \\ e-mail: agungbc@geodesy.its.ac.id
}

\begin{abstract}
Abstrak-Digital Terrain Model (DTM) adalah deskripsi digital dari permukaan medan poin 3D. Pengertian lain tentang DTM merupakan DEM yang telah ditambah dengan unsur-unsur seperti breaklines dan pengamatan selain data asli. Contoh sumber data yang digunakan untuk membuat data DTM yaitu dengan menggunakan data foto udara dan data LiDAR (Light Detection and Ranging). DTM kemudian dapat digunakan untuk pembuatan kontur peta. Ketelitian kontur pada peta RBI diatur dalam Peraturan Kepala Badan Informasi Geospasial No. 15 Tahun 2014. Data yang digunakan dalam penelitian ini yaitu data LiDAR dan foto udara. Pengolahan kedua data tersebut pun memiliki perbedaan. Pengolahan data LiDAR diawali dengan proses editing masspoint dan menghilangkan noise serta spike. Setelah proses editing dilakukan kemudian dilakukan pembuatan model TIN untuk mendapatkan kontur dari DTM data LiDAR. Sedangkan, data foto udara diolah dengan menggunakan cara stereoplotting. Proses stereoplotting ini diawali dengan pembuatan stereomate dan pembentukan model stereo. Hasil stereoplotting tersebut yang kemudian menghasilkan kontur. Setelah terbentuk kontur dari masing-masing data, dilakukan pengujian ketelitian berdasarkan PERKA BIG No. 15 Tahun 2014. Hasil dari penelitian ini yaitu uji LE90 pengolahan data LiDAR sebesar 0,571 $\mathrm{m}$ dan foto udara sebesar $1,099 \mathrm{~m}$. Berdasarkan Perka BIG No. 15 Tahun 2014 pada ketelitian peta skala 1:5000, hasil pengolahan data LiDAR masuk ke dalam klasifikasi kelas 1 dan foto udara masuk kelas 2. Berdasarkan hasil kontur yang dihasilkan, kontur hasil stereoplotting lebih sederhana karena hanya menampilkan kontur yang diperlukan dalam sebuah peta, tidak terdapat titik-titik tinggi hasil perekaman yang tidak diperlukan, dan lebih mudah dipahami pengguna sesuai dengan syarat peta apabila dibandingkan dengan hasil kontur LiDAR.
\end{abstract}

Kata Kunci-Digital Terrain Model, Foto Udara, LiDAR, Uji Ketelitian.

\section{PENDAHULUAN}

$\mathrm{D}$ IGITAL Elevation Model (DEM) adalah gambaran model relief rupabumi tiga dimensi (3D) yang menyerupai keadaan sebenarnya di dunia nyata (real world) divisualisasikan dengan bantuan teknologi komputer grafis dan teknologi virtual reality[1]. DEM memberikan informasi hanya tentang elevasi, sedangkan Digital Terrain Model memberikan informasi tentang elevasi morfologi dan layer permukaan [1].
Pengertian lain tentang DTM merupakan DEM yang telah ditambah dengan unsur-unsur seperti breaklines dan pengamatan selain data asli.

Terdapat beberapa sumber data dalam pembentukan DTM. Contoh sumber data yang digunakan untuk membuat data DTM yaitu dengan menggunakan data foto udara dan data LiDAR (Light Detection and Ranging). Foto Udara adalah citra fotografi hasil perekaman dari sebagian permukaan bumi yang diliput dari pesawat udara pada ketinggian tertentu menggunakan kamera tertentu. Sedangkan, LiDAR adalah teknologi yang menerapkan sistem penginderaan jauh sensor aktif untuk menentukan jarak dengan menembakkan sinar laser yang dipasang pada wahana pesawat udara survei kecil atau helikopter. Salah satu metode untuk pengolahan data foto udara untuk menghasilkan DTM yaitu dengan cara stereoplotting. Sedangkan, pembentukan DTM dengan data LiDAR berdasarkan Triangular Irregular Network (TIN)[2].

Permasalahan yang diangkat dari penelitian ini adalah bagaimana ketelitian kontur dari DTM LiDAR dan foto udara serta bagaimana perbandingan keduanya. Ketelitian kontur pada peta RBI ini berdasarkan pada Peraturan Kepala Badan Informasi Geospasial No. 15 Tahun 2014 [3]. Manfaat yang diharapkan pada penelitian ini adalah dapat memberikan informasi bahwa pembentukan kontur peta RBI dapat berasal dari DTM data LiDAR dan DTM data foto udara serta memberikan analisis perbandingan DTM data LiDAR dan DTM data foto udara dalam pembentukan kontur peta RBI.

\section{METODE PENELITIAN}

A. Data dan Peralatan

1) Data

Data yang digunakan dalam penelitian ini adalah:

1. Data Digital Surface Model LiDAR Sei Mangkei, Sumatera Utara NLP 0719-1242C

2. Data Digital Terrain Model LiDAR Sei Mangkei, Sumatera Utara NLP 0719-1242C

3. Data foto udara Sei Mangkei, Sumatera Utara NLP 0719-1242C (format .tif)

4. Data Pengukuran Lapangan titik GCP dan ICP 
2) Peralatan

Peralatan yang digunakan dalam penelitian ini adalah:

1. Komputer workstation dengan spesifikasi minimal setara dengan i7, 64bit, 8GB RAM, 2TB internal harddisk dengan monitor $120 \mathrm{~Hz}$

2. Software pengolah kata

3. Software pengolah angka

4. Software pengolah data LiDAR

5. Software stereoplotting

6. Kacamata 3D

7. Mouse 3D

\section{B. Lokasi Penelitian}

Data LIDAR dan foto udara dalam penelitian Studi ini berlokasi di Sei Mangkei, Sumatera Utara dengan koordinat $3^{\circ} 7^{\prime} 17.598^{\prime \prime} \mathrm{LU}-3^{\circ} 10^{\prime} 47.7696^{\prime \prime} \mathrm{LU}$ dan 99 ${ }^{\circ} 19^{\prime} 38.6436^{\prime \prime} \mathrm{BT}$ $99^{\circ} 21$ '43.9776" BT.

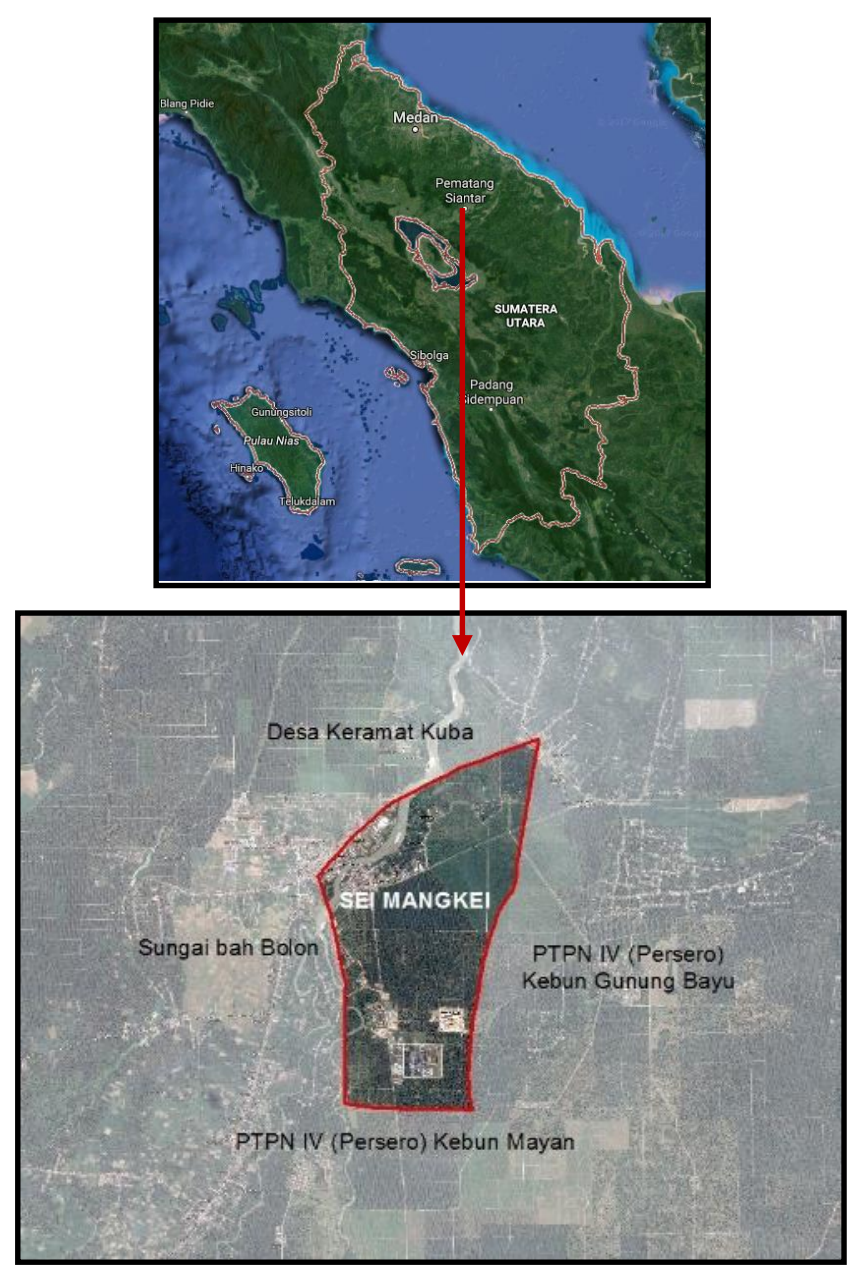

Gambar 1. Lokasi Penelitian

\section{Diagram Alir Pengolahan Data}

Tahapan pengolahan data yang dilaksanakan dalam penelitian ini adalah sebagai berikut :

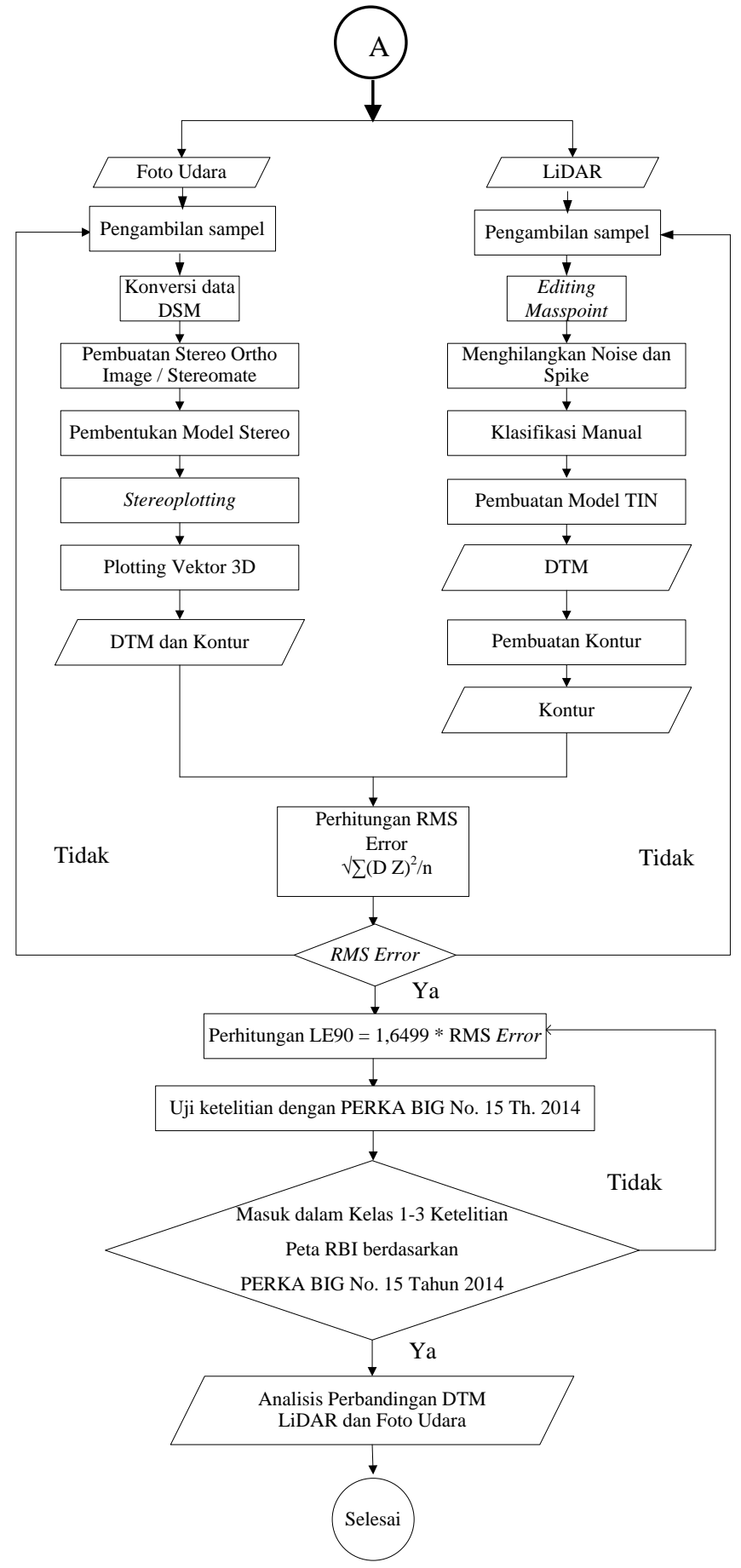

Gambar 2. Diagram alir pengolahan data

\section{HASIL DAN DISKUSI}

\section{A. Stereoplotting (Kontur Foto Udara)}

Kontur foto udara dihasilkan setelah proses pembuatan masspoint selesai dilakukan. Kontur ini menghubungkan daerah-daerah pada area penelitian yang memiliki ketinggian yang sama.

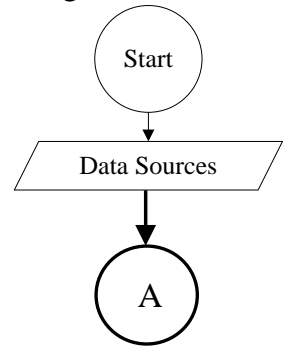




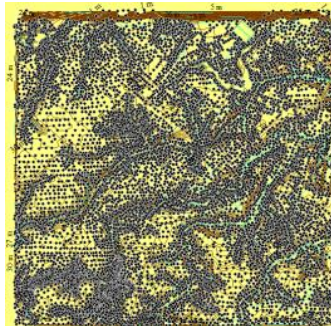

(a)

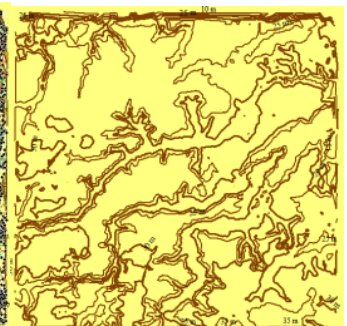

(b)
Gambar 3. (a) Masspoint dan Kontur Foto Udara, (b) Kontur Foto Udara

Titik masspoint yang dihasilkan seperti gambar di atas merepresentasikan suatu ketinggian di permukaan bumi. Hasil masspoint ini memberikan hasil titik yang merepresentasikan koordinat $\mathrm{x}, \mathrm{y}$, dan $\mathrm{z}$. Hasil dari pembuatan masspoint di atas dapat pula digunakan untuk membuat DEM dari Foto Udara. Hasil dari DEM tersebut juga dapat digunakan untuk membuat kontur foto udara.

\section{B. Analisis Stereoplotting (Kontur Foto Udara)}

Pelaksanaan kegiatan stereoplotting menghasilkan data vektor berupa titik-titik sebaran ketinggian atau mass point. Digitasi mass point dibuat di seluruh permukaan tanah sehingga diharapkan merepresentasikan informasi suatu lokasi dipermukaan tanah yang memuat informasi $\mathrm{x}, \mathrm{y}$, maupun $\mathrm{z}$ nya. Perbedaan pembuatan mass point dapat dilihat pada tabel berikut ini :

Tabel 1.

Perbedaan Pembuatan Masspoint

Noma Unsur
Permukan tanah

Digitasi untuk unsur tutupan lahan, seperti sawah, lahan kosong, dan ladang dibuat berdasarkan kondisi tutupan lahannya. Misalnya, titik-titik untuk lahan kosong lebih renggang dari pada titik-titik untuk sawah dan ladang. Digitasi untuk unsur hidrografi, dalam hal ini sungai, dibuat titik-titik di tepi-tepinya. Titik-titik untuk tepian sungai ini dibuat rapat sehingga dapat merepresentasikan adanya gap suatu obyek. Sementara untuk unsur transportasi, dalam hal ini jalan, titiktitiknya dibuat linier mengikuti jalan.

\section{Pembuatan Kontur LiDAR}

Pembuatan kontur dari data LiDAR dilakukan dengan cara buka data DTM hasil pengolahan terakhir.

Gambar 4. Kontur LIDAR

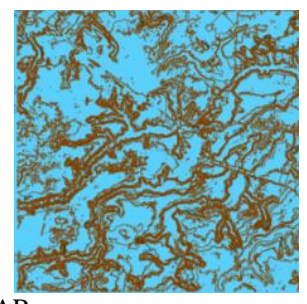

Kontur hasil dari data LiDAR merupakan kontur yang tergantung pada hasil pengolahan DTM. Ketinggian kontur tersebut juga sama dengan ketinggian yang dihasilkan pada data DTM.

\section{Analisis Perbandingan Kontur Foto Udara dan LiDAR}

Seperti telah dijelaskan sebelumnya bahwa kontur dapat dihasilkan dari pengolahan data foto udara dan LiDAR. Berikut perbedaan kontur dari hasil data foto udara dan LiDAR:

Tabel 2.

Perbedaan Kontur LiDAR dan Foto Udara

\begin{tabular}{|c|c|c|c|}
\hline No & $\begin{array}{l}\text { Parameter } \\
\text { Perbedaan }\end{array}$ & Gambar & Penjelasan \\
\hline 1 & Kerapatan & LiDA & $\begin{array}{l}\text { Hasil dari pengolahan } \\
\text { kedua data memiliki } \\
\text { perbedaan yaitu } \\
\text { kerapatan kontur yang } \\
\text { dihasilkan. Pada } \\
\text { kontur LiDAR kontur } \\
\text { yang dihasilkan lebih } \\
\text { rapat apabila } \\
\text { dibandingkan dengan } \\
\text { kontur foto udara Hal } \\
\text { tersebut dikarenakan } \\
\text { kontur yang dihasilkan } \\
\text { sangan dipengaruhi } \\
\text { oleh proses pembuatan } \\
\text { masspoint dan } \\
\text { breakline pada saat } \\
\text { stereoplotting. }\end{array}$ \\
\hline
\end{tabular}

Lanjutan Tabel 2.

Perbedaan Kontur LiDAR dan Foto Udara

\begin{tabular}{|c|c|c|c|}
\hline No & $\begin{array}{l}\text { Parameter } \\
\text { Perbedaan }\end{array}$ & Gambar & Penjelasan \\
\hline 2 & $\begin{array}{c}\text { Objek yang } \\
\text { berkontur }\end{array}$ & Foto Uc & $\begin{array}{l}\text { Berdasarkan kedua } \\
\text { data disamping } \\
\text { terdapat perbedaan } \\
\text { yang cukup signifikan. } \\
\text { Pebedaan tersebut } \\
\text { yaitu pada data LiDAR } \\
\text { terdapat kontur pada } \\
\text { bangunan 3sedangkan }\end{array}$ \\
\hline
\end{tabular}




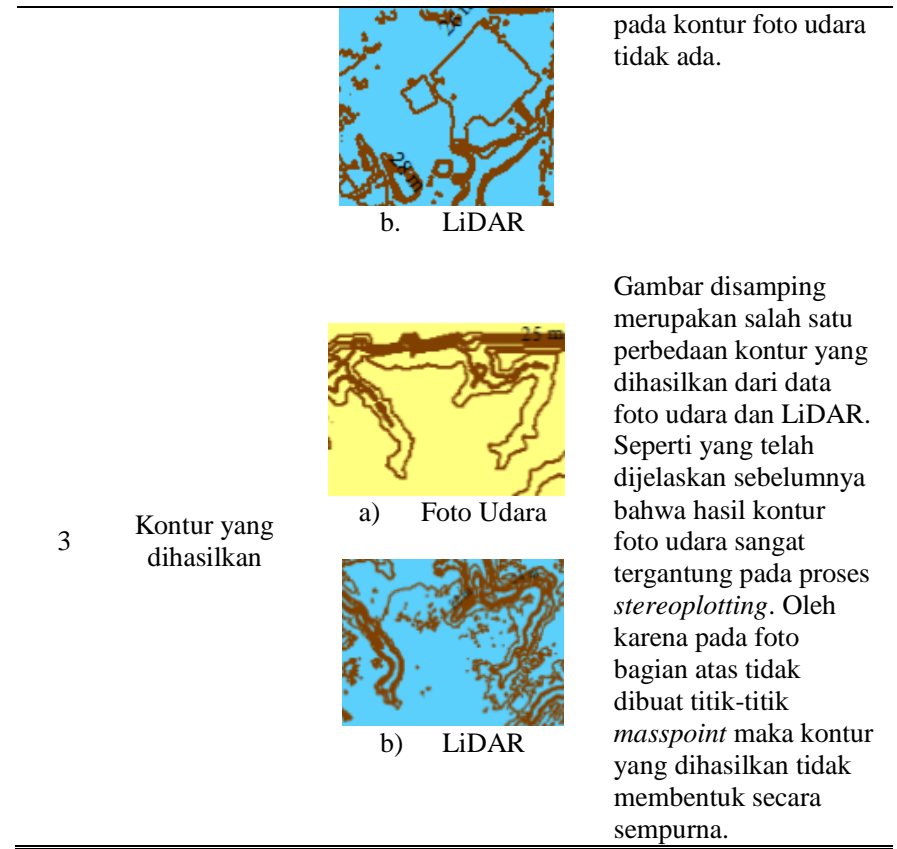

Berdasarkan tabel di atas dapat diambil kesimpulan bahwa kontur data LiDAR tergantung pada Model TIN yang dihasilkan. Sedangkan, untuk kontur data foto udara sangat tergantung pada pembuatan breakline dan masspoint pada proses stereoplotting.

Selain itu, juga dilakukan analisis perbedaan kontur yang dihasilkan keseluruhan. Oleh karena kontur merupakan salah satu komponen dalam peta maka kontur yang baik akan mendukung adanya peta yang baik pula. Sebuah peta yang baik tentunya memiliki syarat yang harus dipenuhi. Syarat-syarat peta yang baik adalah sebagai berikut [4]:

a. Tidak boleh membingungkan

b. Mudah dimengerti atau ditangkap maknanya oleh pengguna peta

c. Dapat memberikan gambaran yang sebenarnya. Ini berarti peta harus cukup teliti dan sesuai dengan tujuan

d. Mudah dilihat sehingga peta harus rapi dan bersih.

Jika dilihat hasil akhir kontur yang dibentuk dari kedua data secara garis besar memang sama. Namun, apabila diteliti kedua hasil kontur tersebut memiliki perbedaan. Berdasarkan syarat peta di atas, tentunya terlihat jelas kontur dari data foto udara lebih memenuhi syarat dibandingkan dengan kontur LiDAR. Kontur yang dihasilkan oleh foto udara lebih sederhana dan tidak membingungkan. Selain itu, kontur hasil LiDAR masih terdapat titik-titik yang tidak perlu ditampilkan. Hal tersebut dapat menyebabkan pengguna sulit untuk mengerti kontur yang disajikan. Serta, jelas terlihat bahwa kontur hasil data foto udara lebih rapi dan bersih.

\section{E. Analisis Uji Akurasi}

Uji akurasi dalam penelitian ini mengikuti perhitungan yang dituangkan dalam Perka BIG No. 15 Tahun 2014. Hal-hal yang perlu dilakukan dalam uji akurasi adalah perhitungan RMS Error dan LE90. Rumus perhitungan RMS Error adalah sebagai berikut :

$$
\mathrm{RMSEz}=\sqrt{ } \sum(\mathrm{D} \mathrm{Z})^{2} / \mathrm{n}
$$

$$
\begin{aligned}
& \text { Keterangan: } \\
& \begin{array}{ll}
\text { RMSEz } & \text { Root Mean Square Error Nilai Z } \\
\text { D Z } & =\text { Selisih Nilai Z } \\
\mathrm{n} & =\text { Jumlah Titik }
\end{array}
\end{aligned}
$$

LE90 adalah ukuran ketelitian geometrik vertikal yaitu nilai jarak yang menunjukkan bahwa 90\% kesalahan atau perbedaan nilai ketinggian objek di peta dengan nilai ketinggian sebenarnya tidak lebih besar daripada nilai jarak tersebut. Nilai LE90 didapatkan dengan persamaan sebagai berikut:

$$
\text { LE90 = 1,6499 x RMSEz }
$$

Keterangan:

$$
\text { LE90 = Ukuran Ketelitian Geometrik Vertikal }
$$

\begin{tabular}{|c|c|c|c|c|c|}
\hline No & $\begin{array}{c}\text { Nama } \\
\text { Titik }\end{array}$ & $\begin{array}{c}\mathrm{Z} \\
\text { (Koor. } \\
\text { GCP/ICP) }\end{array}$ & $\begin{array}{c}\mathrm{Z} \\
\text { (Koor. } \\
\text { LIDAR) }\end{array}$ & $\begin{array}{c}(\mathrm{D} \mathrm{Z}) \\
(\mathrm{m})\end{array}$ & $\begin{array}{c}(\mathrm{D} \mathrm{Z})^{\wedge} 2 \\
(\mathrm{~m})\end{array}$ \\
\hline 1 & S719 & 28,472 & 28,060 & 0,412 & 0,170 \\
\hline \multirow[t]{5}{*}{2} & SME003 & 19,524 & 19,260 & 0,264 & 0,070 \\
\hline & & \multicolumn{2}{|c|}{ Jumlah } & & 0,239 \\
\hline & & \multicolumn{2}{|c|}{ Rata-rata } & & 0,120 \\
\hline & & \multicolumn{2}{|c|}{ RMSE } & & 0,346 \\
\hline & & \multicolumn{2}{|c|}{ Akurasi LE90 } & & 0,571 \\
\hline
\end{tabular}

Hasil pengujian ketelitian pada penelitian ini dilakukan dengan membandingkan nilai $\mathrm{Z}$ yang didapatkan dari pengolahan foto udara dan LiDAR dengan nilai $\mathrm{Z}$ hasil dari nilai GCP/ICP.

Tabel 3

Hasil Titik Koordinat Data LIDAR

Tabel di atas membandingkan koordinat hasil pengolahan data LiDAR dengan koordinat GCP/ICP. Terdapat dua titik GCP/ICP yang dijadikan sebagai pembanding yaitu titik S719 dan SME003. Nilai Z kemudian dihitung nilai RMS Error dan LE90. Nilai RMS Error yang didapatkan sebesar 0,346 $\mathrm{m}$ dan LE90 yang didapatkan sebesar 0,571 m. Hasil dari perhitungan di atas kemudian dibandingkan dengan ketelitian Peta RBI berdasarkan PERKA BIG No. 15 Tahun 2014. Hasil dari perhitungan tersebut dilihat apakah masuk ke dalam syarat minimal nilai ketelitian atau tidak. Hasil perhitungan LE90 tersebut dapat dilihat pada tabel di bawah ini:

Tabel 4.

\begin{tabular}{|c|c|c|c|c|c|}
\hline No. & $\begin{array}{c}\text { Nama } \\
\text { Titik }\end{array}$ & $\begin{array}{c}\mathrm{Z} \\
\text { (Koor. } \\
\text { GCP/ICP) }\end{array}$ & $\begin{array}{c}\mathrm{Z} \\
\text { (Koor. } \\
\text { Foto) }\end{array}$ & $\begin{array}{c}(\mathrm{D} \mathrm{Z}) \\
(\mathrm{m})\end{array}$ & $\begin{array}{c}(\mathrm{D} \mathrm{Z})^{\wedge} 2 \\
(\mathrm{~m})\end{array}$ \\
\hline 1 & S719 & 28,472 & 27,722 & 0,750 & 0,563 \\
\hline
\end{tabular}

Hasil Uji Data LiDAR

\begin{tabular}{ccccc}
\hline \hline & & \multicolumn{3}{c}{ Ketelitian Peta skala } \\
Ketelitian & Hasil uji LE90 & \multicolumn{3}{c}{$1: 5.000$} \\
\cline { 3 - 5 } & $(\mathrm{m})$ & Kelas & Kelas & Kelas \\
& & 1 & 2 & 3 \\
\hline \multirow{2}{*}{ Vertikal } & 0,571 & 1 & 1.5 & 2.5 \\
\hline \hline
\end{tabular}

Berdasarkan tabel di atas hasil uji LE90 yaitu 0,571 m ketelitian peta skala 1:5000 masuk ke dalam klasifikasi kelas 1 . Tabel 5.

Hasil Titik Koordinat Data Foto Udara 


\begin{tabular}{ccccc}
\hline \hline 2 SME003 & 19,524 & 18,954 & 0,570 & 0,325 \\
& Jumlah & & & 0,887 \\
& Rata-rata & & 0,444 \\
& RMSE & & 0,666 \\
\hline
\end{tabular}

Tabel di atas menggambarkan hasil koordinat plotting data foto udara dengan koordinat GCP/ICP. Terdapat dua titik GCP/ICP yang dijadikan sebagai pembanding yaitu titik S719 dan SME003. Nilai Z kemudian dihitung nilai RMS Error dan LE90. Nilai RMS Error yang didapatkan sebesar 0,666 m dan LE90 yang didapatkan sebesar 1,099 m. Hasil dari perhitungan di atas kemudian dibandingkan dengan ketelitian Peta RBI berdasarkan PERKA BIG No. 15 Tahun 2014. Hasil dari perhitungan tersebut dilihat apakah masuk ke dalam syarat minimal nilai ketelitian atau tidak. Hasil perhitungan LE90 tersebut dapat dilihat pada tabel di bawah ini:

Tabel 6.

Hasil Uji Data Foto

\begin{tabular}{ccccc}
\hline \hline \multirow{3}{*}{ Ketelitian } & Hasil uji & \multicolumn{3}{c}{ Ketelitian Peta skala 1:5.000 } \\
\cline { 3 - 5 } & LE90 & Kelas & Kelas & Kelas \\
& & 1 & 2 & 3 \\
\hline Vertikal & 1,099 & 1 & 1.5 & 2.5 \\
\hline \hline
\end{tabular}

Berdasarkan tabel di atas hasil uji LE90 yaitu 1,099 m ketelitian peta skala 1:5000 masuk ke dalam klasifikasi kelas 2 . Pada dasarnya harusnya hasil dari stereoplotting menghasilkan ketelitian yang lebih tinggi dibandingkan dengan hasil data LiDAR. Namun, pada penelitian hasil yang didapatkan adalah sebaliknya. Hal tersebut disebabkan oleh faktor kesalahan ketika melakukan stereoplotting terutama dalam menentukan ground atau tanah.

\section{KESIMPULAN/RINGKASAN}

Hasil dari penelitian ini yaitu uji LE90 pengolahan data LiDAR sebesar $0,571 \mathrm{~m}$ dan foto udara sebesar $1,099 \mathrm{~m}$. Berdasarkan Perka BIG No. 15 Tahun 2014 pada ketelitian peta skala 1:5000, hasil pengolahan data LiDAR masuk ke dalam klasifikasi kelas 1 dan foto udara masuk kelas 2. Berdasarkan hasil kontur yang dihasilkan, kontur hasil stereoplotting lebih sederhana karena hanya menampilkan kontur yang diperlukan dalam sebuah peta, tidak terdapat titik-titik tinggi hasil perekaman yang tidak diperlukan, dan lebih mudah dipahami pengguna sesuai dengan syarat peta apabila dibandingkan dengan hasil kontur LiDAR.

\section{UCAPAN TERIMA KASIH}

Penulis N. D. mengucapkan terima kasih kepada Badan Informasi Geospasial dan PT. Waindo Specterra yang telah menyediakan data hibah foto udara dan LiDAR Sei Mangkei, Sumatera Utara.

\section{DAFTAR PUSTAKA}

[1] T. H. Purwanto, "Digital Terrain Modelling," Univ. Gadjah Mada, 2015.

[2] A. Rahmayudi, A., \& Rizaldy, "Comparison of Semi Automatic DTM from Image Matching with DTM from LIDAR," The International Archives of the Photogrammetry, vol. XLI-B3. 2016.

[3] B. I. Geospasial, Peraturan Kepala Badan Informasi Geospasial No. 15 Tahun 2014 tentang Pedoman Teknis Ketelitian Peta Dasar. 2014.

[4] I. \& T. S., Modul Kartografi. Yogyakarta: Sekolah Tinggi Pertanahan Nasional., 2014. 